\title{
Review of Malaria Situation in Assam with Special Reference to Security Forces
}

\author{
PMP Singh ${ }^{1}$, Rajiva ${ }^{2}$, MS Mustafa ${ }^{3}$
}

\begin{abstract}
Assam, alone, with $2.6 \%$ of the country's population, contributes $>5 \%$ of the total malaria cases in the country. Keeping in view the importance of malaria in the North East and its special significance to the Armed Forces the present study was undertaken to review the malaria situation in Assam.

Data on commonly used parameters of malaria surveillance including drug resistance from 2000 to 2008 were collected. Subsequently the extensive data was compiled in the form of Malaria Atlas Of Assam with choroplath maps at district and PHC level. The number of hospital admissions due to malaria in various service hospitals post 2009 have been taken as an index to measure the success of focused interventions.

District wise mean API of Assam is depicted in Table 1 whereas District wise pattern of reported chloroquine resistance is presented in Figure 1 [4] Total number of admissions due to malaria (both $P$ Vivax and P falciparum species) in service hospitals in the state of Assam for the period 2000 to 2008 is depicted in Table 2. Month wise distribution of cases of malaria in a particular Army field formation (where the revised focused intervention strategy was first implemented) for the year 2009 along with type of infection is given in Table 3.
\end{abstract}

The service personnel deployed in NE region are especially vulnerable as they share the same anthropoecosystem as that of local population but at the same time lack the partial immunity to malaria enjoyed by local population[1].

The data collated by us has shown that the patterns of malaria incidence are not uniform across the state and varies considerably even within the same District. Having API based choroplath maps upto PHC level is of great value for malaria risk assessment for the security forces.

Keywords: Malaria, Malaria in Assam, Choroplath Maps, API, Security Forces, Malaria Surveillance, Chloroquine Resistance

\section{Introduction}

Malaria has been a major public health illness in the North East. The seven sister states contribute 10 to $12 \%$ of total malaria cases; and $14 \%$ of the total malaria morbidity in the country. Assam alone, with $2.6 \%$ of the country's population,

${ }^{1}$ Colonel, Headquarter 5 Mountain Division, 908405.

${ }^{2}$ Formerly Colonel Health and Senior Adviser Community Medicine, Headquarters Central Command (Medical Branch), P.O. Dilkusha, Lucknow, 226002.

${ }^{3}$ Lt Col, Officer Commanding, Station Health Organisation, Chennai.

Correspondence: PMP Singh, Headquarter 5 Mountain Division, 908405.

E-mail Id: Itcolpmpsingh@yahoo.com

Orcid Id: http://orcid.org/0000-0002-5898-5485

How to cite this article: Singh PMP, Rajiva, Mustafa MS. Review of Malaria Situation in Assam with Special Reference to Security Forces. Epidem Int 2017; 2(4): 23-28.

Digital Object Identifier (DOI): https://doi.org/10.24321/2455.7048.201720

ISSN: $2455-7048$ 
contributes $>5 \%$ of the total malaria cases in the country. The state of Assam $\left(24^{\circ} 44^{\prime}\right.$ to $27^{\circ} 45^{\prime} \mathrm{N}$ latitude ; $89^{\circ} 41$ ' to $96^{\circ} 02^{\prime} \mathrm{E}$ longitude) is the second largest state in the Northeast region $\left(78,523 \mathrm{~km}^{2}\right)$ and contributes over $50 \%$ of all malaria cases from the North East and over $5 \%$ of the total reported cases in the country. $P$. falciparum is the predominant parasite species. ${ }^{1,2}$ The region is highly receptive to malaria transmission due to topography, vegetation ( $40 \%$ area is forest), excessive and prolonged rainfall (2 to $3 \mathrm{~m}$ ) which promote vector breeding. High humidity (60 to $90 \%$ ) and warmer climate for most of the year ensures longevity of the vectors. Difficult terrain and poor communication are the other highlights of this state. Because of the presence of distinct physiographic units (Brahmaputra Valley in the North, Barak Valley in the South and hill regions between valleys), sharing of interstate/international borders by 21 districts out of total 23 districts of the state, and a large tribal population of varying ethnicity all major epidemiological types of malaria like forest-related malaria, tribal malaria, border malaria, rural and urban malaria, etc., are encountered. ${ }^{3}$

It was keeping in view the importance of malaria in the North East and its special significance to the armed forces and other such security forces which remain deployed throughout the state owing to various threats and continue to have malaria cases despite routine chemoprophylaxis with weekly chloroquine, the present study was undertaken to review the malaria situation in Assam.

\section{Materials and Methods}

Data on commonly used parameters of malaria surveillance including drug resistance from 2000 to 2008 was collected by personal liaison from different District Malaria Offices. Besides, personal visits were paid to Malaria Research Centre, Sonapur, and ICMR Institute at Dibrugarh, to obtain additional data particularly on vector species prevalent in the state of Assam. Data was cross validated by means of field surveys in endemic areas. The ABER (annual blood examination rate), API (annual parasite incidence) and SPR (slide positivity rate) data was further analyzed for mean and $95 \% \mathrm{Cl}$. This extensive data base enabled drawing of choroplath maps of malaria for the entire state, first at district level and then up to PHC level and compiling them as an atlas titled Malaria Atlas of Assam. This atlas helped in identification of areas of intense transmission and/or areas of chloroquine resistance down up to PHC level. Subsequently, a focused strategy was prepared for prevention of malaria infection among armed forces personnel operating in such areas emphasizing on personal protection, chemo-suppression with an appropriate drug regimen in chloroquine-resistant areas and extensive health education. The same was implemented in an army field formation in upper Assam as a test case under the personal supervision of authors after convincing the commanders of its necessity. The documented incidence of malaria in this particular army field formation in 2009 was taken as an indicator of the success of the strategy followed by its dissemination and roll out on a larger scale. The number of hospital admissions due to malaria in various service hospitals post 2009 has been taken as an index to measure the success of such focused interventions on prevention of malaria infections among vulnerable armed forces personnel.

\section{Results}

District-wise mean API of Assam is depicted in Table 1 whereas district-wise pattern of reported chloroquine resistance is presented in Fig. $1 .{ }^{4}$ Districts were further classified on the basis of API. The number of districts showing a particular API during the study period is presented in Fig. 2. District-wise API from 2000 to 2008 is shown in Fig. 3. Total number of admissions due to malaria (both $P$. vivax and $P$. falciparum species) in service hospitals in the state of Assam for the period 2000 to 2008 is depicted in Table 2. Month-wise distribution of cases of malaria in a particular army field formation (where the revised focused intervention strategy was first implemented) for the year 2009 along with type of infection is given in Table 3. The incidence of malaria in the state of Assam from 2009 to 2013 along with total number of malaria cases admitted in the previously referred five service hospitals in the state of Assam is given in Table $4 .^{5}$ 
Table 1.District-Wise Mean ABER, Mean API and Mean PF \%: 2000-2008

\begin{tabular}{|c|c|c|c|c|}
\hline S. No. & District & Mean ABER & Mean API (95\% CI) & Mean Pf \% (Range) \\
\hline 1. & Barpeta & 6.03 & $1.31(0.82$ to 1.81$)$ & $53.04(39.58$ to 69.89$)$ \\
\hline 2. & Bongaigaon & 9.01 & $3.33(2.30$ to 4.36$)$ & $93.08(88.55$ to 94.16$)$ \\
\hline 3. & Cachar & 6.11 & $2.40(1.98$ to 2.82$)$ & $99.33(97.35$ to 99.82 \\
\hline 4. & Darrang & 7.56 & $8.30(6.20$ to 10.40$)$ & $15.97(8.52$ to 25.43$)$ \\
\hline 5. & Dhemaji & 5.66 & $1.98(0.67$ to 3.29$)$ & $38.89(2.06$ to 100$)$ \\
\hline 6. & Dhubbri & 7.29 & $1.10(0.85$ to 1.35$)$ & $89.84(85.89$ to 93.53$)$ \\
\hline 7. & Dibrugarh & 6.94 & $0.04(0.02$ to 0.06$)$ & $78.70(72.73$ to 88.76$)$ \\
\hline 8. & Goalpara & 9.09 & $5.33(4.12$ to 6.53$)$ & $84.19(74.06$ to 90.98$)$ \\
\hline 9. & Golaghat & 8.89 & $0.69(0.14$ to 1.24$)$ & $53.22(22.80$ to 93.56$)$ \\
\hline 10. & Hailakandi & 9.95 & $7.74(5.97$ to 9.51$)$ & $98.92(98.00$ to 99.69$)$ \\
\hline 11. & Jorhat & 7.24 & $0.18(0.08$ to 0.29$)$ & $62.04(14.02$ to 95.24$)$ \\
\hline 12. & Kamrup & 7.30 & $2.39(1.70$ to 3.08$)$ & $80.81(76.30$ to 89.77$)$ \\
\hline 13. & Karbi Anglong & 21.41 & $18.69(16.45$ to 20.92$)$ & $86.04(82.94$ to 88.17$)$ \\
\hline 14. & Karimganj & 5.03 & $0.52(0.33$ to 0.71$)$ & $90.21(83.98$ to 95.13$)$ \\
\hline 15. & Kokrajhar & 9.68 & $6.88(5.27$ to 8.49$)$ & $76.67(66.51$ to 82.08$)$ \\
\hline 16. & Lakhimpur & 8.16 & $3.68(1.16$ to 6.20$)$ & $12.72(0.21$ to 42.13$)$ \\
\hline 17. & Morigaon & 6.11 & $1.02(0.23$ to 1.81$)$ & $60.79(43.24$ to 64.20$)$ \\
\hline 18. & Nagaon & 10.40 & $2.45(2.01$ to 2.89$)$ & $60.62(24.4$ to 78.41$)$ \\
\hline 19. & Nalbari & 6.21 & $1.72(0.94$ to 2.49$)$ & $79.60(68.32$ to 86.15$)$ \\
\hline 20. & North Cachar Hills & 13.27 & $14.51(12.76$ to 16.26$)$ & $74.82(64.81$ to 82.28$)$ \\
\hline 21. & Sibsagar & 5.67 & $0.05(0.02$ to 0.08$)$ & $82.58(70.21$ to 90.91$)$ \\
\hline 22. & Sonitpur & 8.93 & $3.14(2.02$ to 4.26$)$ & $38.33(24.04$ to 59.23$)$ \\
\hline 23. & Tinsukia & 6.18 & $1.26(0.79$ to 1.74$)$ & $29.78(18.22$ to 49.59$)$ \\
\hline
\end{tabular}

DISTRICT WISE PATTERN OF REPORTED CHLOROQUINE RESISTANCE

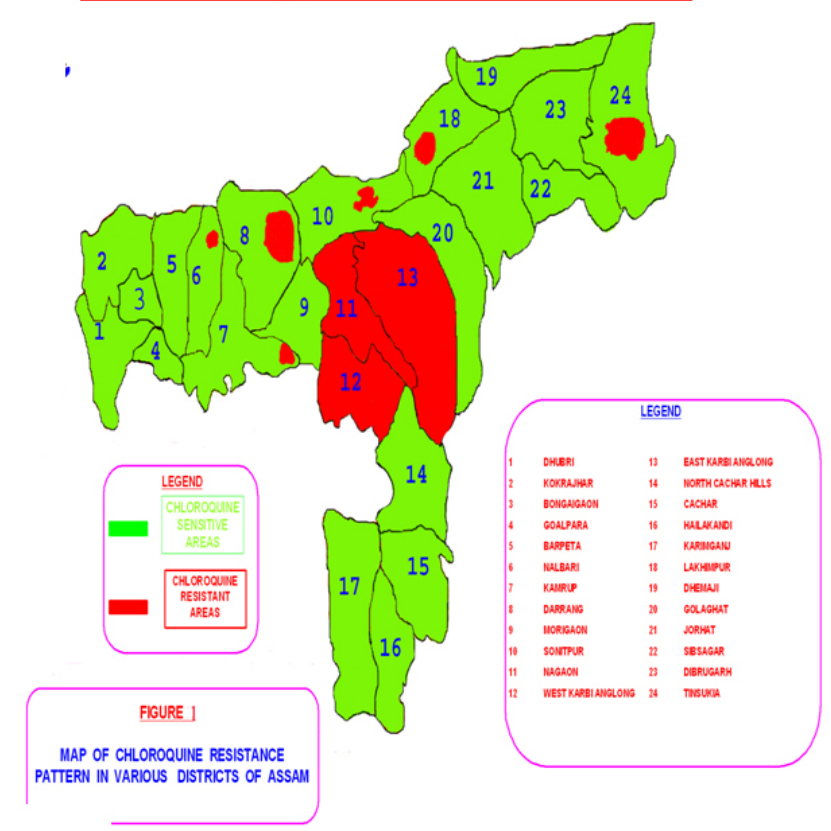

Figure 1 


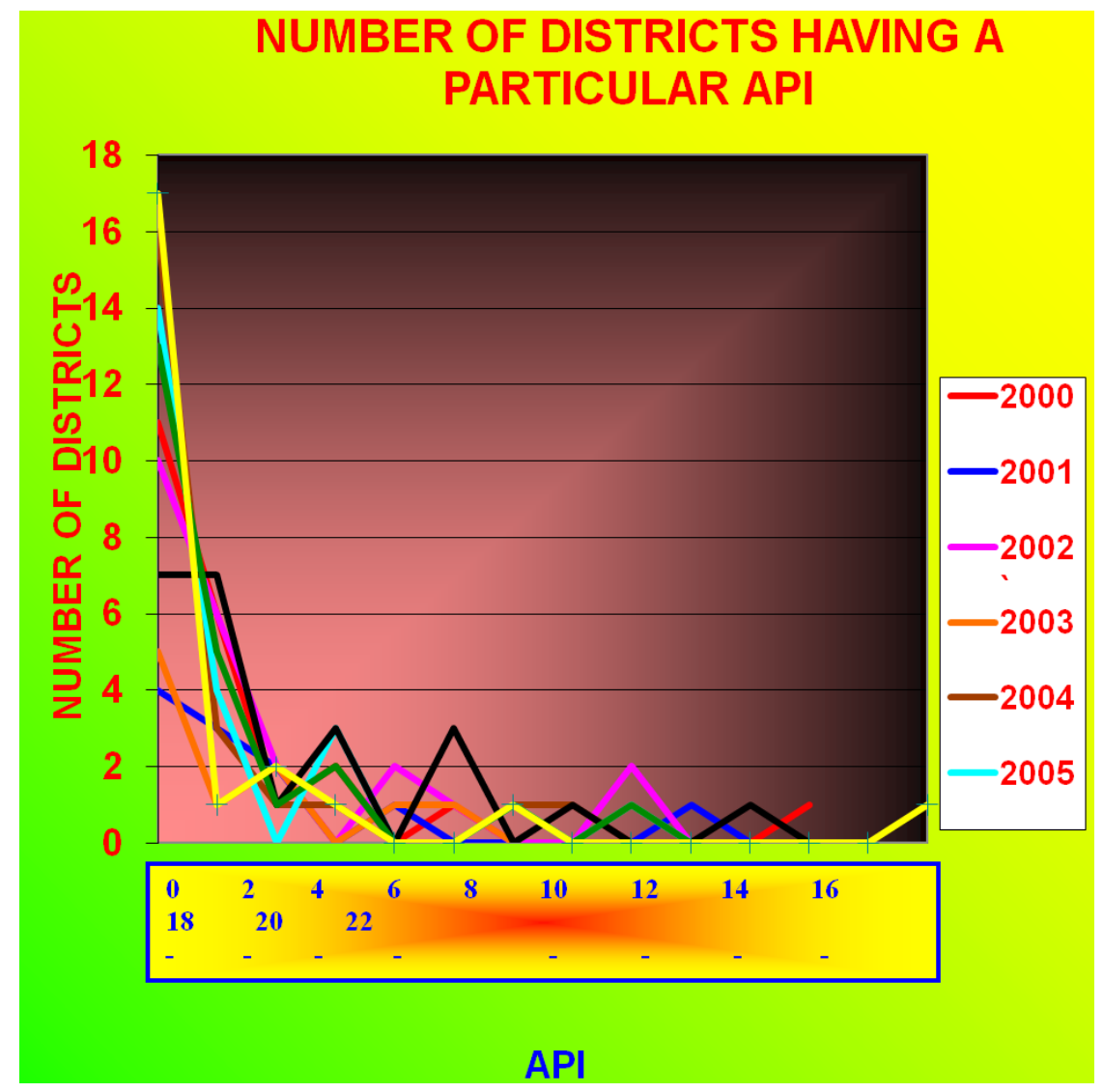

Figure 2

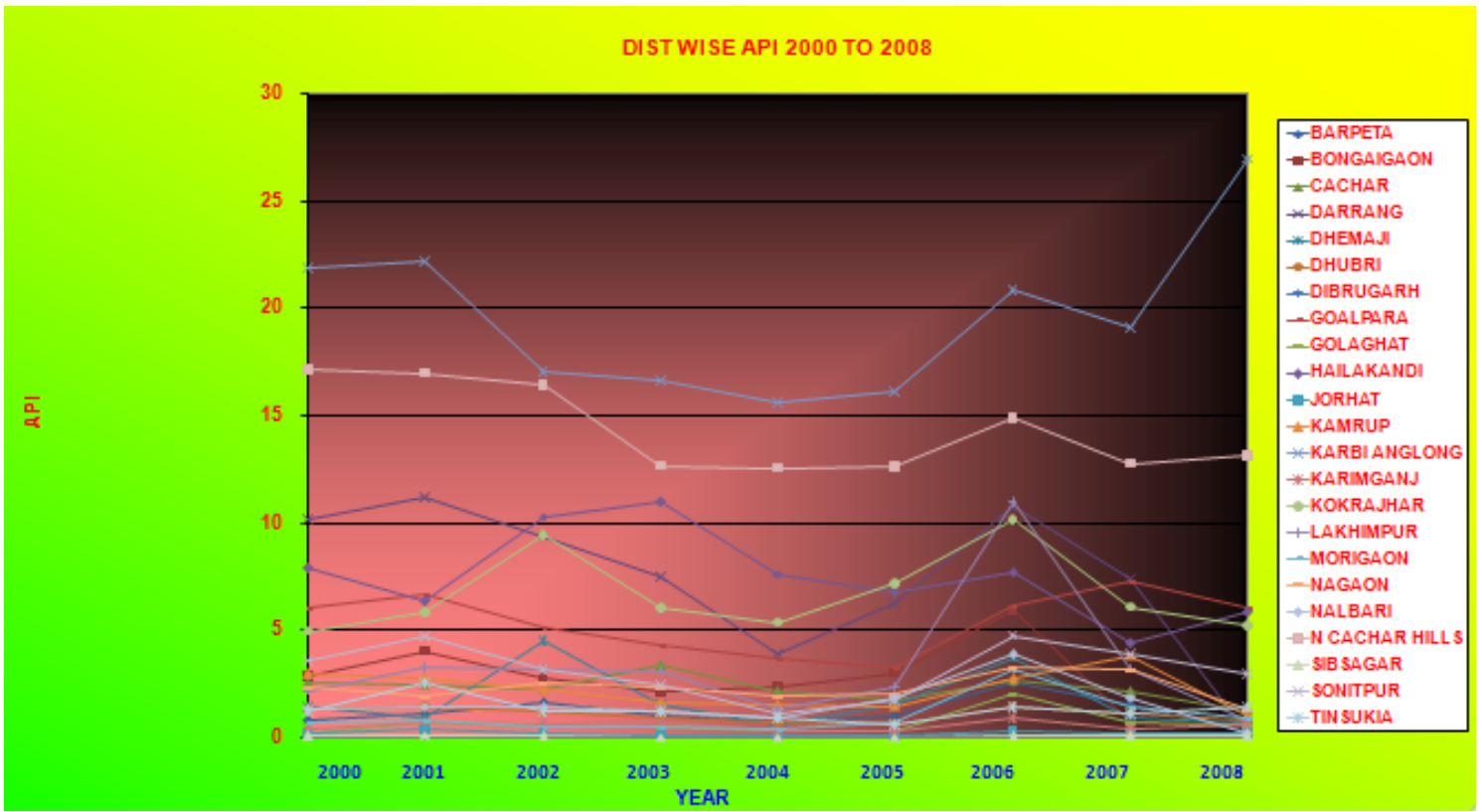

Figure 3 
Table 2.Total Number of Admissions due to Malaria (both $P$. vivax and $P$. falciparum Species) in Six Service Hospitals in the State of Assam for the Period 2000 to 2008

\begin{tabular}{|c|c|c|c|c|c|c|c|c|c|c|c|}
\hline S No. & Name of & \multicolumn{10}{|c|}{ Total Admissions } \\
\cline { 3 - 15 } & Hospital & $\mathbf{2 0 0 0}$ & $\mathbf{2 0 0 1}$ & $\mathbf{2 0 0 2}$ & $\mathbf{2 0 0 3}$ & $\mathbf{2 0 0 4}$ & $\mathbf{2 0 0 5}$ & $\mathbf{2 0 0 6}$ & $\mathbf{2 0 0 7}$ & $\mathbf{2 0 0 8}$ & Total \\
\hline 01. & $151 \mathrm{BH}$ & 105 & 129 & 78 & 89 & 107 & $\mathbf{7 5}$ & 98 & 66 & 61 & 808 \\
\hline 02. & $155 \mathrm{BH}$ & 126 & 144 & 75 & 94 & 124 & 93 & 103 & 78 & 68 & 908 \\
\hline 03. & $160 \mathrm{MH}$ & 31 & 61 & 26 & 78 & 48 & 19 & 11 & 02 & 02 & 278 \\
\hline 04. & $162 \mathrm{MH}$ & 29 & 56 & 22 & 69 & 45 & 17 & 07 & 01 & 01 & 247 \\
\hline 05. & $180 \mathrm{MH}$ & 03 & 05 & 03 & 06 & 04 & 22 & 02 & 05 & 06 & 056 \\
\hline 06. & $5 \mathrm{AFH}$ & 108 & 114 & 66 & 78 & 102 & 81 & 90 & 63 & 57 & 759 \\
\hline \multicolumn{1}{|l}{ Total } & 402 & 509 & 270 & 414 & 430 & 307 & 311 & 215 & 195 & 3053 \\
\hline
\end{tabular}

Table 3.Month-Wise Distribution of Cases of Malaria in an Army Field Formation for the Year 2009 along with Type of Infection (Post Targeted Intervention)

\begin{tabular}{|c|c|c|c|c|}
\hline \multirow{2}{*}{ S. No. } & \multirow{2}{*}{ Month } & \multicolumn{3}{|c|}{ Number of Cases of Malaria } \\
\cline { 3 - 5 } & & P. falciparum & P. Vivax & Total \\
\hline 1. & Jan 2009 & 01 & 00 & 01 \\
\hline 2. & Feb 2009 & 00 & 00 & 00 \\
\hline 3. & Mar 2009 & 00 & 00 & 00 \\
\hline 4. & Apr 2009 & 00 & 00 & 00 \\
\hline 5. & May 2009 & 00 & 00 & 00 \\
\hline 6. & Jun 2009 & 02 & 00 & 02 \\
\hline 7. & Jul 2009 & 03 & 01 & 06 \\
\hline 8. & Aug 2009 & 01 & 00 & 03 \\
\hline 9. & Sep 2009 & 00 & 01 & 02 \\
\hline 10. & Oct 2009 & 02 & 00 & 00 \\
\hline 11. & Nov 2009 & 00 & 00 & 02 \\
\hline 12. & Dec 2009 & 14 & 00 & 00 \\
\hline & Total & 00 & 16 \\
\hline
\end{tabular}

Note: The malaria incidence works out to 1.3 cases per thousand of the population under investigation

Table 4.Malaria in Assam, North-East India, 2009-2013

\begin{tabular}{|c|c|c|c|c|c|c|}
\hline Year & $\begin{array}{c}\text { Population } \\
\text { (millions) }\end{array}$ & $\begin{array}{c}\text { No. of } \\
\text { Cases }\end{array}$ & API & $\begin{array}{c}\text { P. falciparum } \\
\%\end{array}$ & Deaths & $\begin{array}{c}\text { Total No of Hospital Admissions due to Malaria } \\
\text { (All Types) in Six Service Hospitals of Assam }\end{array}$ \\
\hline 2009 & 31.27 & 91413 & 2.92 & 73 & 63 & 190 \\
\hline 2010 & 31.35 & 66716 & 2.13 & 72 & 36 & 141 \\
\hline 2011 & 32.03 & 47397 & 1.48 & 73 & 45 & 113 \\
\hline 2012 & 32.45 & 29999 & 0.92 & 69 & 13 & 101 \\
\hline 2013 & 32.91 & 19542 & 0.59 & 77 & 07 & 102 \\
\hline
\end{tabular}

From Fig. 2, it is observed that there was an epidemic in the year 2006 . The number of districts showing an API of 0-2 was 7 as compared to 10 to 15 in the other years of the study period. However, it is also observed from Fig. 3 that this epidemic was contributed to a large extent by five districts, viz., Darrang, Goalpara, Golaghat, Kokrajhar and Sonitpur.

\section{Discussion}

Malaria is endemic in most Northeastern states of India with predominance of $P$. falciparum infections. ${ }^{1,6}$ Outbreaks in civil and even in service population are a regular event. ${ }^{1,7,8}$
Transmission of the malaria pathogen is persistent and is maintained mostly by Anopheles minimus; other vectors are Anopheles dirus and Anopheles fluvitalis. ${ }^{1,9-11}$ The service personnel deployed in NE region are especially vulnerable as they share the same anthropo-ecosystem as that of local population due to their extensive deployment in counter-insurgency operations and border management but at the same time lack the partial immunity to malaria enjoyed by locals due to their regular turnover. ${ }^{1}$

The data collated by us has shown that the patterns of malaria incidence are not uniform across the state and varies considerably even within the same district. Having 
API-based choroplath maps up to PHC level is of great value for malaria risk assessment for the security forces operating in that area as it facilitates planning of focused interventions with greater and better compliance instead of general advisories. Such data is also a valuable input for commanders planning short-term operations against insurgents, etc.

\section{Conflict of Interest: None}

\section{References}

1. Patra SS, Dev V. Malaria related morbidity in central reserve police force personnel located in the north eastern states of India. J Human Ecol 2004; 15 (4): 255-59.

2. Sharma J, Dutta P, Khan SA. Epidemiological study of malaria cases in North East region of India. Indian J Med Microbiol [serial online] 2016 [cited 2017 May 2]; 34: 261-62. Available from: http://www.ijmm.org/ text.asp?2016/34/2/261/176843.

3. Singh PMP, Bhalwar R, Mehta VK et al. Malaria in Assam: A Challenge. Indian J Community Med 2009 Apr; 34(2): 94-96.

4. Khaund K. Personal communication. State Health Directorate; Government of Assam. 15 Jul 2008.

5. Dev V, Sharma VP, Barman K. Mosquito-borne diseases in Assam, north-east India: Current status and key Challenges. WHO South-East Asia Journal of Public
Health Jan-Jun 2015; 4(1-2).

6. Dev V, Hira CR, Rajkhowa MK. Malaria attributable morbidity in Assam, Northeastern India. Annals of Tropical Medicine \& Parasitology 2001; 95: 789-96.

7. Jaiswal P, Srinivasan S, Mehta VK et al. Malaria on the move: Ecological considerations for the armed forces. MJAFI 2007; 63(2): 112-14.

8. Dev V, Ansari MA, Hira CR et al. An outbreak of $P$. falciparum malaria due to Anopheles minimus in Central Assam, India. Indian Journal of Malariology 2001; 38: 32-38.

9. Regional Medical Research Centre. Mosquito fauna of North East India with special reference to the medically important vectors. Regional Medical Research Centre, NE Region (Indian Council of Medical Research) 2003.

10. Dutta P, Khan SA, Khan MA et al. Results and discussion. In: Sharma CK, Doloi P, Baruah NK, editors. Mosquito Fauna of North East India with Special Reference to the Medically Important Vectors. Regional Medical Research Centre, N.E. Region (Indian Council Of Medical Research) Dibrugarh, Assam 2003; 30.

11. Dev V, Bhattacharyya PC, Talukdar R. Transmission of malaria and its control in the northeastern region of India. J Assoc Physicians India 2003 Nov; 51: 1073-76.

Date of Submission: 2017-10-16 Date of Acceptance: 2017-12-16 